\title{
A Crítica Freudiana ao Reducionismo Biológico
}

The Freudian criticism against biological reducionism

André Luis Masiero,

André Luis Muniz de

Oliveira, Fabiano Amantéa

Ragnoli \& Larissa Canella

Gozzoli

Pontifícia Universidade

Católica de Minas Gerais, Campus de Poços de Caldas
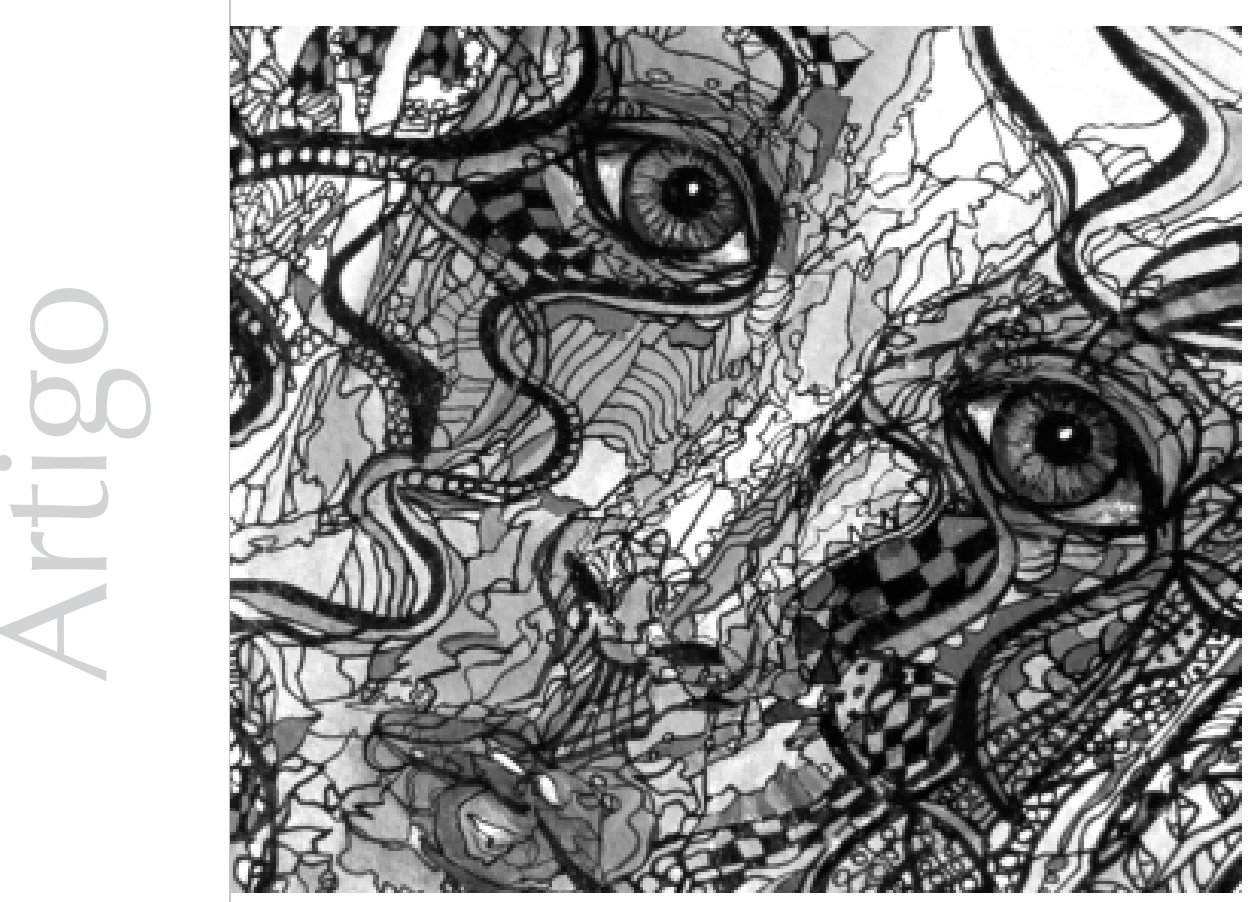


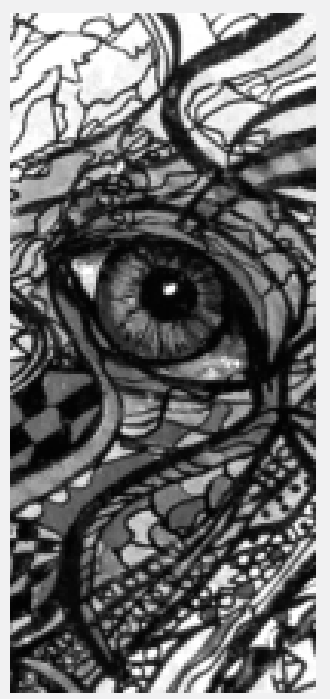

Resumo: Atualmente ressurge uma tendência reducionista biológica no âmbito da psicanálise. Neste ensaio, apresentamos a forma como Freud empreendeu sua crítica contra essa concepção através de duas rupturas epistemológicas: a teoria sexual e a teoria dos sonhos.

Palavras-chave: psicanálise, reducionismo biológico, teoria sexual, teoria dos sonhos.

Abstract: A biological reductionism tendency in the psychoanalytical sphere reappears nowadays. In this essay we present the way Freud undertook his critics against this conception through two epistemological ruptures: the sexual theory and the theory of dreams.

Key words: psychoanalysis, biological reductionism, sexual theory, theory of dreams.

Atualmente ressurge, no âmbito da psicanálise mundial, o interesse pelo caráter biológico da obra de Freud. Grupos de pesquisadores vêm sendo formados pelo mundo com o objetivo de esquadrinhar o papel que a neurobiologia desempenhou na construção da psicanálise, avaliando se uma retomada e/ou continuação desse pensamento determinaria novos rumos para o conhecimento acerca do inconsciente.

Vem ganhando destaque mundial uma nova disciplina que pretende agregar, em um só campo de conhecimento, a psicanálise e as neurociências, a neuropsicanálise. Segundo o neuropsicólogo Mark Solms (2004), pioneiro na área, as descobertas das neurociências vêm confirmando muitas das teses psicanalíticas, o que Freud havia previsto no início do século XX. Esse é o motivo pelo qual a psicanálise vem ressurgindo no turbilhão do debate neurocientífico contemporâneo após um declínio nos últimos 20 anos, de acordo com Solms.

O advento de novos medicamentos também tem estimulado o interesse científico na procura da determinação biológica das desordens mentais. A descoberta dos primeiros psicofármacos, na década de 50 , foi anunciada com grande entusiasmo. Segundo Rodrigues (2003), foi uma verdadeira "revolução psicofarmacológica", apesar dos intensos efeitos colaterais e baixa eficiência desses medicamentos, muitas vezes até mesmo agravando o quadro psicopatológico dos usuários. Nos últimos anos, pesquisas têm resultado em fármacos mais bem tolerados pelos usuários, diminuindo seus temidos efeitos colaterais.

A genética molecular é uma das áreas científicas que mais tem se popularizado e prometido, para um breve futuro, a prevenção de desordens mentais através da manipulação genética, embora as pesquisas na área da psiquiatria ainda sejam incipientes. De acordo com Ojopi, Gregório, Guimarães, Fridman \& Dias Neto (2004), a genética molecular poderá elucidar as causas da esquizofrenia, abrindo a possibilidade de melhores tratamentos e prevenção. 


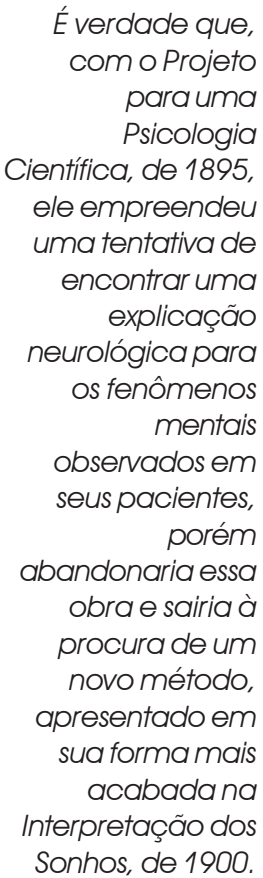

A neurologia, a genética e a farmacologia têm engendrado especulações de que brevemente todo o tratamento das desordens mentais se reduzirá a poucas e simples manipulações de ordem biológica, relegando não só a psicanálise, mas também outras ciências psicológicas e seus métodos terapêuticos a um plano secundário.

Especificamente no campo psicanalítico atual, surgem muitos questionamentos frente à retomada das teses biológicas. A neuropsicanálise pretende apoiar toda a produção de conhecimento sobre o inconsciente na neurociência, afirmando, entre outras extravagâncias, que o id, o eu e o supereu têm localizações precisas no cérebro.

Outro segmento entende que é possível essa conjunção, mas não necessária para a sobrevivência da psicanálise, tratando-se somente da criação de uma nova disciplina. Se essa conjunção é viável, e que resultados renderá, ainda é prematuro afirmarmos com segurança.

Outras linhas de pensamento na psiquiatria têm questionado a real utilidade da psicanálise no mundo moderno frente ao surgimento de medicamentos mais eficientes e rápidos na eliminação de sintomas psicopatológicos (Roudinesco, 2000).

Esses fatos podem estar nos indicando que, com a tentativa de (re)estabelecer o "rigor científico" da psicanálise, talvez estejamos assistindo a um ressurgimento do mais puro e simples reducionismo biológico, uma tendência a submeter todos os fenômenos humanos a um único sistema de leis explicativas e que reivindica um status privilegiado de verdade.
O presente ensaio tem o objetivo de avaliar esse momento crítico pelo qual passa a psicanálise. Para tanto, retomaremos pontos fundamentais da obra freudiana: a Teoria Sexual e a Interpretação dos Sonhos. Essas duas colunas, com a Metapsicologia, formam o alicerce do pensamento freudiano, e, a partir daí, podemos mostrar caminhos para uma crítica ao reducionismo.

Com a Metapsicologia, Freud estabeleceu a definição do objeto da psicanálise: o inconsciente; este, porém, não é definido apenas como substantivo, mas como adjetivo, assumindo um sentido muito diferente dos seus predecessores. No âmbito da chamada Primeira Tópica (1900-1920), o inconsciente é um local do aparelho mental desconhecido pela consciência, onde estão armazenados afetos recalcados pouco acessíveis pelo eu.

É verdade que, com o Projeto para uma Psicologia Científica, de 1895, ele empreendeu uma tentativa de encontrar uma explicação neurológica para os fenômenos mentais observados em seus pacientes, porém abandonaria essa obra e sairia à procura de um novo método, apresentado em sua forma mais acabada na Interpretação dos Sonhos, de 1900.

Com a Teoria Sexual, Freud desvinculou a sexualidade - até então naturalizada organicamente e moralizada culturalmente na forma de instinto reprodutivo - da genitalidade. Essa ruptura foi trabalhosa e levou Freud a erigir um novo arsenal conceitual para explicar, entre outros fatos humanos, a sexualidade infantil na determinação dos destinos do indivíduo e da cultura.

Com a Interpretação dos Sonhos, ele lança luz à via de acesso ao inconsciente e a seus significados, sobrepujando o entendimento 
dos sonhos como mera atividade cerebral desprovida de sentido e de interesse científico.

De saída, podemos dizer que o primeiro questionamento de Freud (1896) foi justamente o papel dos distúrbios orgânicos (neurológicos, tóxicos, genéticos, etc.) na determinação dos sintomas histéricos. Levando em consideração também a possibilidade de uma simples "simulação histérica" ou "fingimento" - hipótese descartada, embora aceita por boa parte dos contemporâneos de Freud -, essas controvérsias foram tanto motivo das suas primeiras contendas com o saber científico estabelecido quanto um verdadeiro móbile da psicanálise.

Portanto, antes de sairmos em busca dos substratos neurofisiológicos do Ödipuskomplex ou do gene determinante dos lapsus linguae, vale determo-nos por um momento na obra freudiana a fim de apontarmos uma possível interpretação acerca de uma problemática aberta na psicanálise contemporânea e que, ao que tudo indica, está longe de ser encerrada.

\section{Da etiologia da histeria à teoria sexual}

Há um texto de Freud ${ }^{1}$ pouco comentado que foi um marco na transição de seus estudos neurológicos para os psicológicos. Quando esteve em Paris, como aluno de Jean Martin Charcot, entre 1885 e 1886, este Ihe propôs que realizasse um trabalho que diferenciasse as paralisias motoras orgânicas das histéricas. A primeira lição que aprendeu com o mestre foi que era possível extrair conjecturas neurológicas a partir da observação dos estados clínicos, método não aceito pelos alemães (Manonni, 1994). De fato, Freud já trazia essa inquietação de Viena. Havia sintomas aparentemente de origem orgânica, mas que, numa observação mais atenta, se revelavam de origem estritamente psicológica.

Originalmente escrito em francês, o texto final veio a lume sete anos depois de pronto, com o título Algumas considerações para um estudo comparativo das paralisias motoras orgânicas e histéricas. Foi um dos resultados do estágio de Freud em Paris.

Aqui ele apresenta uma série de argumentos favoráveis à conclusão de que a histeria teria um fundo psicológico, afirmando que haveria paralisias estranhas que se comportavam à revelia da anatomia. As paralisias histéricas pareciam destituir a configuração nervosa.

"Na histeria, o ombro ou a coxa podem estar mais paralisados do que a mão ou o pé. Podem surgir movimentos dos dedos enquanto o segmento proximal ainda está absolutamente inerte" (Freud 1895, pp. 205-6).

Assim, observou Freud, a delimitação da paralisia histérica era muito precisa, o que seria impossível se o distúrbio em questão tivesse origem orgânica, como uma intoxicação ou uma lesão cerebral. As paralisias histéricas, ainda, sempre se apresentavam com uma intensidade maior que a orgânica, embora durassem menos tempo e fossem acompanhadas de dificuldades no plano psicológico, como depressão, ansiedade, pesadelos, etc.

Tendo à frente esses dados, seria coerente imaginar que se trataria apenas de simulação do paciente. No entanto, alguns estados histéricos, se fossem simulados, causariam tal fadiga corporal que rapidamente o doente desistiria de seus "sintomas". Além disso, não
"Na histeria, o ombro ou a coxa podem estar mais paralisados do que a mão ou o pé. Podem surgir movimentos dos dedos enquanto o segmento proximal ainda está absolutamente inerte"

Freud
1 Neste trabalho utilizamos a Edição Standard Brasileira das Obras Completas, de $S$. Freud, de 1996, da editora Imago, porém, sempre que possivel, comparamos a tradução com o inglês e espanhol, bem como seguimos as observações criticas de Bettelheim (1984); Carone \& Souza (1989) e Roudinesco (1998). Os trabalhos de Freud citados trazem a data original de publicação. 
era possível tantos casos de simulação, como os observados na Salpêtrière. Havia, portanto, algum fenômeno a ser entendido e talvez, até aquele momento, negligenciado pela Medicina.

Parecia não haver dúvidas de que existiam paralisias cuja origem não podia ser creditada ao físico. O mestre Charcot já o teria mostrado. Ainda nesse trabalho, Freud esboça uma explicação para a dinâmica psicológica da formação sintomática do distúrbio. Todo o psiquismo seria revestido de cargas afetivas às quais o ego deveria encaminhar-se convenientemente, ou por meios motores, ou por encadeamentos mentais. Se o indivíduo fosse incapaz de eliminar as cargas afetivas, essas formariam um precipitado mental - como um corpo estranho - que futuramente desencadearia algum sintoma. A grande novidade desse trabalho é o rascunho de uma explicação de como um afeto poderia sedimentar-se no sistema nervoso e desencadear um sintoma físico facilmente observável.

Ainda que as explicações psicodinâmicas para a histeria prevalecessem na primeira fase do pensamento freudiano, permanecia em aberto o papel da hereditariedade na causação das neuroses. Também como um dos frutos de sua passagem pelo Salpêtrière, Freud dedicar-se-ia à questão da hereditariedade dos distúrbios mentais, um tema indispensável aos médicos do final do século XIX. Mesmo que houvesse uma dinâmica mental inconsciente subjacente à histeria, a qual Freud perseguia, tudo indicava que essa forma de funcionamento mental era determinada hereditariamente, aliás, como acreditava Charcot.

Nesse momento, a ciência da hereditariedade despontava na Medicina como uma grande promessa no controle epidemiológico da loucura e da "degeneração". Um bom exemplo era Francis Galton, um primo de Charles Darwin, que, em 1869, propôs que o Estado regulamentasse os casamentos como meio de garantir que, dessas uniões, fossem gerados os melhores descendentes humanos, tanto para o Estado quanto para a própria coesão da estrutura familiar, o que representaria, entre outras vantagens, um ganho econômico para a nação. Com essa prática, no longo prazo, a "raça humana" desenvolver-se-ia biologicamente, chegando futuramente a um estágio superior de evolução. Utópico, mas prestigiado no meio científico europeu, o inglês dizia que teria comprovado, através do estudo de genealogias de famílias ilustres inglesas, que a loucura e a inteligência eram categorias hereditárias. Galton seguia duas regras simples: 1) Os "melhores indivíduos" reproduziriam os melhores descendentes; 2) A mistura dos "bem-dotados" com os "degenerados" poderia macular os bons exemplares raciais. Poucos contestavam essas premissas (Masiero, 2002).

Freud (1896) não negava a importância da hereditariedade na determinação das neuroses, mas, segundo sua experiência médica, dizia que muitos distúrbios eram considerados hereditários inadequadamente. O caso conhecido como Miss Lucy era um exemplo. Haveria um certo exagero no princípio da hereditariedade irrestrita acompanhada de uma prematuridade científica frente aos dados disponíveis, pois, afinal, a predisposição genética para algum distúrbio psíquico só poderia ser comprovada depois de os sintomas já se terem instalado. O simples fato de uma neurose ser mais freqüente em determinadas famílias não representaria, necessariamente, um fenômeno hereditário. Sequer os 
levantamentos genealógicos eram precisos, pois eram sujeitos a muitas interferências dos relatores.

A hereditariedade também não explicava o problema da "escolha da neurose". Sabia-se que determinadas famílias poderiam apresentar uma recorrência de neuroses acima da média populacional, porém nada explicava o motivo pelo qual, na passagem das gerações, as neuroses se apresentavam de maneiras diversas. Numa geração, haveria uma histeria; noutra, uma obsessão; na próxima, uma psicose, etc. A crítica cabal à hereditariedade, porém, foi a questão das "causas concorrentes" das neuroses, isto é, as influências ambientais que impulsionariam, em maior ou menor grau, a predisposição aos distúrbios mentais, como o esgotamento nervoso, a sobrecarga intelectual, a fadiga física, as intoxicações, etc. Mesmo que houvesse uma causação hereditária, sem esses agentes, talvez a neurose ficasse latente e nunca se manifestasse. O papel relativo da hereditariedade e desses agentes era uma questão à espera de resposta, e era justamente nessa fenda explicativa que a psicanálise se inseria.

Evidentemente, a intenção de Freud (1896), nesse trabalho, não era demolir o edifício da hereditariedade, mas certamente apontar, quase solitariamente, as tendências ideológicas e as falhas das explicações das causas das neuroses. O que Freud combatia era um certo otimismo científico desmedido, que tomava a hereditariedade como explicação total para todos os males, tentando abrir caminhos para uma cura definitiva dos sofrimentos humanos. A hereditariedade isolada, portanto, não seria o suficiente para explicar a etiologia das neuroses. Freud (1896b) empenha-se, então, não só na elucidação de outras possibilidades etiológicas das neuroses mas também de seus significados para o indivíduo, a partir, sobretudo, dos atos experimentados no cotidiano.

Seu ponto de partida é o método de Joseph Breuer. As experiências traumáticas passadas deixariam marcas mnêmicas no indivíduo. Essas marcas poderiam retornar simbolicamente na forma de neurose, independentemente do tempo em que foram deixadas. A terapêutica consistia em trazer à tona os traumas e, "tendo assim localizado a cena, eliminamos o sintoma ao promover, durante a reprodução da cena traumática, uma correção subseqüente do curso psíquico dos acontecimentos que então ocorreram" (Freud, 1896b). Caberia ao psicanalista descobrir qual foi a cadeia associativa que realizou o paciente entre o sintoma neurótico apresentado e a sua causa traumática (uma experiência vivida). O intrigante, nessa concepção, é que, segundo os relatos dos pacientes de Freud, no momento em que ocorreu, a experiência parecia uma cena banal, não sendo vivida como traumática. Nesse ponto, Freud é enfático. Qualquer que seja a cadeia associativa de recordações do paciente, ao final, chega-se a uma lembrança infantil e de ordem sexual, não necessariamente de aparência traumática. Evidentemente, uma agressão sexual pode deixar marcas traumáticas indeléveis, mas haveria casos em que uma simples insinuação ou contato corporal casual teria desencadeado sintomas neuróticos futuros. Prevendo as críticas, defende-se dizendo que essa conclusão é derivada de sua experiência como médico, e que ele mesmo teria relutado em aceitá-la e trazê-la a público.

No entanto, Jean Martin Charcot, Hippolyte Bernheim e Rudolf Chrobak - um ginecologista colega de Freud na Universidade "tendo assim localizado a cena, eliminamos o sintoma ao promover, durante a reprodução da cena traumática, uma correção subseqüente do curso psíquico dos acontecimentos que então ocorreram"

Freud 
de Viena -, em certas ocasiões, teriam comentado idéia semelhante, mas nunca levaram isso a público em artigos ou conferências, apenas em comunicações informais (Mannoni, 1994).

Assim, os casos de neuroses não explicados através da hereditariedade poderiam ter origem traumática sexual. Haveria, portanto, alguma sexualidade na infância, o que contradizia as premissas biológicas até então, de que só poderia haver sexualidade quando o corpo já estivesse pronto para a procriação, após a puberdade.

De acordo com Roudinesco (1998, p. 772), "ao mostrar que as atividades infantis - os tipos de sucção, a masturbação, as brincadeiras com o corpo ou com as fezes, a alimentação, a defecação, etc. - são fontes de prazer e autoerotismo, Freud destrói o velho mito do 'paraíso dos amores infantis. '"

A descoberta da sexualidade infantil prégenital, isto é, anterior à unificação das pulsões sob o primado do genital (pênis, clitórisvagina), foi um grande passo no entendimento da causação das neuroses e um rompimento com a sexologia biológica. Na obra Três Ensaios sobre a Teoria da Sexualidade, de 1905, Freud inaugura uma sexualidade como estruturante da subjetividade. Ora, se a sexualidade fosse restrita ao biológico, não haveria uma multiplicidade de comportamentos e manifestações sexuais como os observados no ser humano, e o sexo seria, como nos animais, periódico e somente para procriação. Definitivamente, não parecia que a sexualidade humana se manifestasse dessa forma.

\section{Os sonhos}

Até o advento da psicanálise, os sonhos eram entendidos sob dois aspectos: pela sabedoria popular, como fenômeno místico revelador do futuro ou da vontade dos deuses, e pela ciência, como simples produto da atividade fisiológica cerebral sem nenhum significado e inútil para o desvendamento de qualquer aspecto anímico humano. Sob esses pontos de vista, encerrava-se toda a discussão a respeito.

Mas Freud, ao contrário, a partir de suas observações dos estados psicopatológicos, perseguia a hipótese de que todos os sonhos, mesmo aqueles aparentemente absurdos, carregavam um sentido próprio quase sempre desconhecido, dissimulado por uma série de operações inconscientes e imediatamente vinculado à vivência cotidiana ou remota do sonhador. Cerca de dez anos antes da publicação da Interpretação dos Sonhos, quando tratava da Sr. a Emmy von N., começou a perceber que os sonhos poderiam ser um ponto de partida para associações que conduziriam até idéias inconscientes subjacentes aos sintomas. O papel da psicanálise seria justamente a revelação do sentido dessas idéias inconscientes. Esse caso ainda se reveste de suma importância, pois apresenta uma série de reformulações metodológicas, como o abandono da hipnose, o início da associação livre e a descoberta do papel da sexualidade nas neuroses.

Freud começa a contestar a concepção neurofisiológica do sonho do século XIX, a qual, carente de conhecimentos profundos acerca da própria atividade cerebral, fechavase sobre si mesma. Como psicanalista, negouse ainda a aceitar que um fenômeno deveras trivial e comum a todos os seres humanos nada poderia revelar a seu respeito. Se não houvesse fatos que justificassem o estudo científico dos sonhos, também não havia motivos para desprezá-los. 
O fato de os sonhos remeterem a aspectos da vida em vigília não constituía grande novidade. Na Interpretação dos sonhos, Freud apresenta um longo levantamento de estudos realizados que apontam essa conclusão, porém as explicações disponíveis no período ainda deixavam em aberto muitas lacunas, entre elas "As condições de sua origem, sua relação com a vida anímica de vigília, sua dependência de estímulos que se impõem à percepção durante o estado de sono, as muitas peculiaridades de seu conteúdo que repugnam ao pensamento desperto, a incoerência entre suas imagens de representação e os afetos a elas ligados e, por fim, seu caráter transitório, a maneira como o pensamento de vigília os põe de lado como algo que lhe é estranho, e os mutila ou extingue na memória - todos esses problemas, e outros ainda, vêm aguardando esclarecimento há muitas centenas de anos e, até agora, nenhuma solução satisfatória foi proposta para eles" (Freud, 1901, p. 573).

Fica claro, nessa passagem, que a sua intenção era inaugurar uma nova ciência do sonho, uma vez que essas questões não poderiam ser respondidas pela ciência do cérebro do início do século XX nem depois de centenas de anos de especulação. Aliás, eram problemas levantados muito mais pela mística sabedoria popular que pela ciência.

Em suas observações clínicas, Freud notou que as estruturas psicopatológicas eram análogas à dinâmica onírica de indivíduos normais. Essa constatação foi absolutamente intrigante e indicava que os limites entre o normal e o patológico se esvaíam na medida em que sua teoria mental avançava. Convém lembrar que boa parte dos sonhos apresentados na Interpretação dos Sonhos eram seus próprios. Isso distanciava a psicanálise cada vez mais dos saberes médicos que exigiam parâmetros claros entre o normal e o patológico, e entre sujeito e objeto.

Seu ponto de partida foi a questão das fontes de estimulação dos sonhos, isto é, quais fatores eliciavam a atividade onírica. Inúmeros estudos e especulações indicavam três tipos de estímulos dos sonhos: 1) estímulos sensoriais externos: quando levemente adormecido, os órgãos dos sentidos humanos conseguem ainda captar estímulos exteriores como sons, luzes e sensações táteis, e, partir daí, elaborar um sonho; 2) estímulos internos subjetivos: como nas alucinações ou ilusões, a atividade cerebral cria imagens, sons ou sensações enquanto estamos adormecidos; essas sensações se organizam na forma de sonhos; 3) estímulos somáticos orgânicos: se dormirmos privados de alguma necessidade fisiológica, tentaremos compensar a falta através do sonho. Se tivermos fome, sonharemos com alguma comida, com sede, sonharemos com água, e assim por diante. Entende-se assim o ditado popular: o sonho é o guardião do sono, isto é, para que o desconforto proveniente da privação não atrapalhe uma necessidade fisiológica fundamental (o sono), haveria sempre uma tendência para sonhos agradáveis, na tentativa de compensar uma falta. Portanto, o sonho, na primeira acepção de Freud, seria a "realização de um desejo".

Esses três pontos não entram em conflito com a premissa inicial de que os sonhos guardam sempre algum vínculo com a vida em vigília, como já haviam apontado Wundt e Strümpell. A grande novidade inicia-se quando Freud aponta uma outra fonte de estimulação onírica, isto é, as fontes psíquicas. A questão central colocada na teoria era saber se existiriam sonhos cujas fontes estimuladoras 
É sobre a repressão, paradoxalmente, que, embora seja o motivo das frustrações humanas, estruturar-se-iamo indivíduo e a civilização. não passariam pelo somático. Sabemos atualmente que existem sonhos que não se encaixam totalmente nas três fontes descritas acima, sendo que talvez a maioria deles parece distanciar-se tanto da realidade que causam grande surpresa ao próprio sonhador (Freud, 1916). Isso é facilmente constatável na atividade clínica. Freud criticava a psiquiatria do final do século XIX por negar uma certa autonomia do psíquico frente ao somático, como se isso representasse algum retrocesso científico em direção a uma antiga "metafísica da mente". Mesmo não havendo a aceitação, pela ciência, de que os sonhos seriam fenômenos psíquicos, por outro lado, essa mesma ciência não apresentava nenhum argumento contrário convincente; assim, nada impedia Freud de partir da premissa de que haveria fontes estritamente psíquicas de estimulação onírica.

Para assegurar que essas fontes tinham papel central na determinação dos sonhos, Freud expôs várias constatações que podem servir à análise de qualquer tipo de produção do inconsciente, como a arte, o folclore, os chistes, os atos falhos e também nas formações sintomáticas.

Primeiramente, a memória parecia estendida na atividade onírica. Os sonhos traziam conteúdos mnêmicos há muito tempo "esquecidos" pelo sonhador e que pareciam inacessíveis em vigília. Nesse ponto, as impressões formadas na tenra infância eram predominantes. Freud já trazia a idéia de uma certa memória indissolúvel desde seu contato com as experiências com hipnose, de $\mathrm{H}$. Bernheim. Se o esquecimento não significava uma destruição do conteúdo mnêmico, logo deveria haver um mecanismo que guardasse esse conteúdo, impedindo seu contato com a consciência e outro que permitisse a sua manifestação de maneira dissimulada. $\mathrm{O}$ primeiro é a repressão, e o segundo, a simbolização.

Os sonhos se valem de imagens e linguagem simbólica, cujo sentido é desconhecido pelo próprio sonhador. É como se o inconsciente lançasse mão de um recurso para adequar os desejos e impulsos a uma linguagem aceitável conscientemente. Basicamente, isso é o que faz a transformação do conteúdo onírico latente, isto é, o "real" significado do desejo ou fantasia, em conteúdo manifesto, ou seja, a maneira como o desejo ou fantasia são representados no sonho. Na definição freudiana, o simbolismo é uma alusão ou uma comparação de elementos (imagem, palavra) aparentemente desconectados, mas que guardam entre si uma relação que, mesmo obscura, é passível de revelação.

Aparentemente, a consideração dos sonhos como "realização de desejo" não explicaria um outro fenômeno onírico fundamental: os pesadelos. Se a função dos sonhos fosse resguardar o sono, como explicar a formação desses tipos de sonhos? Afinal, nada seria mais perturbador à tranqüilidade do sono que os pesadelos. É verdade que a palavra "pesadelo" aparece pouquíssimas vezes na obra de Freud, certamente não por esquivarse do assunto, mas, sim, por considerá-lo um tipo de sonho próximo aos dos sonhos agradáveis. No aparelho mental, atuaria uma força repressora para tentar debelar os impulsos violentos próprios do ser humano, presentes desde a infância. É sobre a repressão, paradoxalmente, que, embora seja o motivo das frustrações humanas, estruturarse-iam o indivíduo e a civilização. No período de sono, a censura atuante no aparelho mental seria amenizada, deixando os impulsos hostis, próprios do ser humano, mas inimagináveis conscientemente, quase totalmente livres para se manifestarem. $\mathrm{O}$ eu, sentindo-se 
ameaçado, choca-se com esses impulsos, gerando uma ansiedade perturbadora do sono.

É interessante notar que Freud, mesmo conhecendo com profundidade as determinações neurofisiológicas do fenômeno, buscava uma explicação fundamentalmente psíquica para os sonhos; os pesadelos pareciam comprovar definitivamente sua tese.

\section{Conclusão}

O título do artigo de Solms (2004), em uma revista de divulgação científica, passa ao público a impressão de que a psicanálise esteve fora dos debates científicos nos últimos anos e que agora, com a neuropsicanálise, "Freud está de volta". Isso é falso e nem de longe se trata de um deslize casual, mas de uma manobra retórica do autor para posicionar-se como o salvador de uma teoria, ou o cientista que resgatou a psicanálise de um suposto ostracismo. Basta uma olhadela no ritmo das publicações de revistas e livros no Brasil e no mundo, nos anais de congressos, nos cursos de formação, etc., das últimas décadas, para se constatar que Freud "não está de volta", pelo simples fato de nunca ter deixado o âmbito das ciências psicológicas, que sempre necessitam recorrer a um ou outro aspecto do pensamento psicanalítico.

A tendência de medicalizar a psicanálise e colocá-la nos parâmetros científicos positivos é antiga e vem sendo, ao mesmo tempo, criticada e aclamada. Critica-se a psicanálise por ser especulativa e não permitir falsear hipóteses e criar modelos de verificação experimental. Freud já estava atento a esse problema quando abriu a discussão sobre a análise leiga. A psicanálise, para seu próprio criador, não deveria ficar restrita a uma categoria profissional, mesmo que tenha surgido no seio da Medicina. Sabe-se também que Freud colocava a clínica como o local por excelência de produção do conhecimento psicanalítico, insatisfeito que estava com os resultados dos métodos tradicionais. Ora, se quisesse criar modelos experimentais, Freud o teria feito; afinal, teve todas as oportunidades para isso, ao passar treze anos na universidade cursando Medicina e sofrendo pressões para que renunciasse às suas idéias. O abandono ou desistência de criar um modelo neurológico, evidenciado pelo Projeto para uma psicologia científica, e a publicação subseqüente da Interpretação dos Sonhos, sua obra máxima concluída menos de cinco anos depois, apresenta-nos uma clara ruptura epistemológica. Freud não abandonou o Projeto por falta de opção nem admitiu que essa obra fora um fracasso; abandonou-o devido à maturação de seu método, que impôs rupturas com modelos científicos dominantes, processo semelhante ao que ocorre com qualquer cientista. Os críticos da psicanálise, que pretendem (re)colocá-la numa suposta "ordem científica", parecem desprezar o fato de que a obra freudiana é construída e reconstruída o tempo todo. Freud nunca hesitou em abandonar ou reformular suas concepções quando observava que não mais davam conta de explicar ou intervir nos fenômenos que investigava. Um exemplo clássico é o rápido abandono da hipnose, a busca por métodos mais concretos e que poderiam ser compartilhados pelos seus pares. Uma afirmação sua do final do século XIX não necessariamente deve ser entendida como a sua última palavra, visto que produziu até poucas semanas antes de falecer, em 1939. Portanto, não é possível afirmar que Freud aguardava um aprimoramento da neurologia para adequar a psicanálise a outros parâmetros científicos. Aliás, essa é uma das principais 
justificativas dos neuropsicanalistas na tentativa de ajustar a metapsicologia a um modelo cerebral. No início de sua produção, talvez nutrisse essa esperança, mas certamente abandonou-a, o que fica mais evidente a partir da década de 1920.

Toda essa celeuma parece mostrar-nos dois caminhos futuros. Por um lado, podemos decretar o fracasso da tentativa de fundar uma ciência da subjetividade e apelarmos para as soluções rápidas oferecidas pelas terapias medicamentosas. Por esse caminho, certamente haverá ganhos de poder e prestígio para a psicanálise, mas não necessariamente ganhos científicos, éticos ou filosóficos. O sucesso das terapias místicas, que se autoproclamam atualmente como "alternativas", e a revelação de que os novos antidepressivos podem desencadear comportamentos suicidas (Amorim, 2004) são claras evidências de que o prestígio social de uma disciplina não é decorrência da sua precisão científica.

Tudo indica, porém, que a construção de um modelo interdisciplinar neuropsicanalítico é irreversível. Apontando um segundo caminho, melhor fariam os psicanalistas, antes de censurar a neuropsicanálise e as tendências biologizantes reducionistas, se abrissem uma crítica contra a tentativa de submeter toda a psicanálise a um modelo único, indicando que a sua existência não depende de provas advindas de outros modelos epistemológicos. A psicanálise tem um método independente e estruturado de produção de conhecimento, e a neuropsicanálise - como a psicofarmacologia, a psiquiatria genética, etc. - é tão somente mais uma área de estudos dentre tantas outras que pode ser salutar, desde que não tente englobar a pluralidade das abordagens psicológicas. 


André Luis Masiero
Mestre e Doutor em Psicologia pela USP - Ribeirão Preto
Professor-assistente da PUC-MG - Poços de Caldas
Coordenador-adjunto do Curso de Psicologia PUC-MG - Poços de Caldas
Coordenador do Núcleo de Estudos Psicanalíticos
Rua Padre Francis Cletus Cox, 1661 - Jd. Country Club
Poços de Caldas-MG CEP: 37701-355
Email:masiero@yahoo.com Tel.: (35) 3729-9249
André Luis Muniz de Oliveira
Fua Vivaldi Leite Ribeiro, 422, Cascatinha, Poços de Caldas-MG. CEP: 37701-029.
Fabiano Amantéa Ragnoli
Rua Chile 310, Jardim Quissisana, Poços de Caldas-MG. CEP 37701-226
Larissa Canella Gozzoli
Rua de Luizi, 77, Santa Ângela, Poços de Caldas-MG. CEP 37701-281
Alunos do 5.9 semestre de Psicologia da PUC-MG - Campus de Poços de Caldas
Integrantes do Núcleo de Estudos Psicanalíticos PUC-MG - Poços de Caldas

AMORIM, Cristina. Remédio Amargo. In Folha de S. Paulo, Caderno Mais! 17/10 2004.

BETTELHEIM, Bruno. Freud e a Alma Humana. São Paulo: Cultrix, 1984.

CARONE, Marilene \& SOUZA, Paulo C. A Edição Brasileira de Freud. In Sigmund Freud e o Gabinete do Dr. Lacan. São Paulo: Editora Brasiliense, 1989

FREUD, S. (1886). Relatório sobre meus Estudos em Paris e Berlim. Edição Standard Brasileira das Obras Completas de S. Freud, vol. I. R.J.: Editora Imago, 1996.

(1895). Algumas Considerações para um Estudo Comparativo das Paralisias Orgânicas Motoras e Histéricas. Edição Standard Brasileira das Obras Completas de S. Freud, vol. I. R.J.: Editora Imago, 1996

(1896). A Hereditariedade e a Etiologia das Neuroses. Edição Standard Brasileira das Obras Completas de S. Freud, vol. III. R.J. Editora Imago, 1996.

(1896b). A Etiologia da Histeria. Edição Standard Brasileira das Obras Completas de S. Freud, vol. III. R.J.: Editora Imago, 1996.

(1900). A Interpretação dos Sonhos, cap. I. C. Os Estímulos e as Fontes do Sonho. Edição Standard Brasileira das Obras Completas de S. Freud, vol. IV, R.J.: Editora Imago, 1996.

(1901). Sobre os Sonhos. Edição Standard Brasileira das Obras Completas de S. Freud, vol. V. R.J.: Editora Imago, 1996.
(1906). Três Ensaios sobre a Teoria da Sexualidade-As Aberrações Sexuais. Edição Standard Brasileira das Obras Completas de S. Freud, vol. VII. R.J.: Editora Imago, 1996.

(1916). O Simbolismo nos Sonhos. Edição Standard Brasileira das Obras Completas de S. Freud, vol. XV. R.J.: Editora Imago, 1996.

MANNONI, Octave. Freud: uma Biografia llustrada. Rio de Janeiro: Jorge Zahar Editores, 1994

MASIERO, André Luis. Psicologia das Raças e Religiosidade no Brasil. Psicologia: Ciência e Profissão, 22, n.o 1, 2002, pp.66-79.

OJOPI Elida P. B.; GREGÓRIO S. P.; GUIMARÃES P. E. M.; FRIDMAN, C.; DIAS NETO, E. O Genoma Humano e as Perspectivas para o Estudo da Esquizofrenia. Revista de Psiquiatria Clínica, 31, n.o 1. São Paulo: Lemos, 2004, pp. 9-18.

PERÓN, Paula Regina. Da Sugestão à Análise da Transferência: a Noção de Cura Psicanalítica no Início da Obra Freudiana. Mental, 2, n.o 2. Barbacena, junho 2004, pp. 35-53.

RODRIGUES, Joelson Tavares. A Medicação como Única Resposta: uma Miragem do Contemporâneo. Psicologia em Estudo, 8, n.o 1. Maringá, 2003, pp. 13-22.

ROUDINESCO, Elisabeth; PLON, Michel. Dicionário de Psicanálise. Rio de Janeiro: Jorge Zahar Editores, 1998.

ROUDINESCO, Elisabeth. Por que a Psicanálise? Rio de Janeiro: Jorge Zahar Editores, 2000.

SOLMS, Mark. Freud Está de Volta. Scientific American Brasil, 3, n.ำ 25. São Paulo, 2004, pp. 50-56. 